\title{
Recurrence of Ovarian Cancer with Placental Metastasis: A Case Report
}

\author{
Michiko Honda ${ }^{a}$ b Manabu Yamada $^{a}$ Toshio Kumasaka ${ }^{c}$ \\ Taiki Samejima $^{a, d}$ Hirohisa Satoh ${ }^{e}$ Mitsuhiro Sugimoto ${ }^{a, f}$ \\ ${ }^{a}$ Department of Obstetrics and Gynecology, Japanese Red Cross Medical Center, \\ Tokyo, Japan; ${ }^{b}$ Department of Obstetrics and Gynecology, University Hospital \\ Mizonokuchi, Teikyo University School of Medicine, Kawasaki, Japan; 'Department of \\ Pathology, Japanese Red Cross Medical Center, Tokyo, Japan; ${ }^{\mathrm{d} D e p a r t m e n t}$ of Obstetrics \\ and Gynecology, The University of Tokyo Hospital, Tokyo, Japan; ${ }^{\mathrm{e} D e p a r t m e n t ~ o f ~}$ \\ Obstetrics and Gynecology, Tachikawa Kyosai Hospital, Tachikawa, Japan; ' Department of \\ Obstetrics and Gynecology, Tohto Bunkyo Hospital, Tokyo, Japan
}

\section{Keywords}

Ovarian cancer · Recurrence · Pregnancy · Sudden examination · Placental metastasis

\begin{abstract}
A 39-year-old primiparous Japanese female was admitted to the obstetrical emergency department of our hospital because of respiratory distress resulting from a large amount of pleural effusion, soon after a caesarean delivery (CD) at another hospital. While she was undergoing the $C D$, a giant ovarian tumour was identified. However, the tumour could not be removed at that facility and she was transferred to our hospital. Three days after the CD, a left salpingo-oophorectomy was performed with the purpose of controlling pleural and peritoneal effusions. Based on her past treatment history and the information gathered from this
\end{abstract}




\section{Case Reports in Oncology}

Case Rep Oncol 2017;10:824-831

DOI: $10.1159 / 00047995$

(C) 2017 The Author(s). Published by S. Karger AG, Base www.karger.com/cro

Honda et al.: Recurrence of Ovarian Cancer with Placental Metastasis: A Case Report

surgery, recurrence of ovarian cancer was considered the final diagnosis. Earlier, at the age of 37 years, she had been diagnosed with stage IC ovarian adenocarcinoma arising from a mature cystic teratoma detected after a right salpingo-oophorectomy. These kinds of situations of accidental detection of recurrent advanced ovarian cancer in a newly pregnant patient in the emergency department are rare. Amongst them, we have identified an extremely rare case showing placental metastasis. The important lesson learnt from this case report is that detailed medical interviews and physical examinations are crucial when a pregnant woman visits a hospital without a letter of referral, especially in the third trimester of pregnancy.

(C) 2017 The Author(s)

Published by S. Karger AG, Basel

\section{Introduction}

Ovarian cancers diagnosed during pregnancy are very rare [1]. Most cases are detected in the first trimester of pregnancy due to the widespread early-stage use of ultrasound [2,3], and therefore, most obstetricians do not usually encounter pregnant patients with advanced recurrent ovarian cancer. There are sometimes delays in responding to symptoms, especially on sudden examination during the third trimester of pregnancy, unless the possibility of presence of ovarian cancer is assumed. Because of its rarity, little is known about metastasis of advanced ovarian cancer during pregnancy. Furthermore, placental metastasis is extremely rare and its management remains unresolved. Here, we present a pregnant patient diagnosed accidentally with recurrence of advanced ovarian cancer in our obstetrical emergency department.

\section{Case Report}

A 39-year-old primiparous Japanese female was transferred to the obstetrical emergency department of our hospital for the management of respiratory distress after a caesarean delivery (CD), performed at another hospital. In that hospital, an emergency CD was performed because of non-reassuring foetal status after premature rupture of the membranes in the 36th week of pregnancy. During CD, a giant tumour and approximately $2.5 \mathrm{~L}$ of ascites were detected in the patient's upper abdomen. However, this situation could not be controlled in that hospital and the patient along with her baby was transferred to our hospital. This ovarian tumour could not be detected by the physician before CD, as the patient had suddenly visited that hospital in the 31st week of pregnancy without a referral.

Laboratory findings upon admission to our hospital were as follows: haemoglobin levels of $7.3 \mathrm{~g} / \mathrm{dL}$, lactate dehydrogenase levels of 1,633 IU/L, carcinoembryonic antigen levels of $3,100 \mathrm{ng} / \mathrm{mL}$, and carbohydrate antigen 125 levels of $271 \mathrm{U} / \mathrm{mL}$. A contrast-enhanced computed tomography scan indicated the presence of a $24-\mathrm{cm}$ ovarian tumour with a large amount of pleural and peritoneal effusion (Fig. 1a-c).

On referring to information about her past treatment history, obtained later from the earlier hospital, recurrence of the ovarian cancer was diagnosed. At the age of 37 years, the patient had undergone a salpingo-oophorectomy for an ovarian tumour on the right side. 


\section{Case Reports in Oncology}

Case Rep Oncol 2017;10:824-831

DOI: $10.1159 / 00047995$

(C) 2017 The Author(s). Published by S. Karger AG, Base www.karger.com/cro

Honda et al.: Recurrence of Ovarian Cancer with Placental Metastasis: A Case Report

Although there were no signs of invasion and dissemination outside the right ovary, as the capsule of the tumour was ruptured during the resection, the pathological diagnosis was adenocarcinoma stage IC (b), pT1c (b) NxMx, arising from the mature cystic teratoma (Fig. $2 \mathrm{a}, \mathrm{b}$ ). The patient refused further surgery and adjuvant chemotherapy, and subsequently dropped out from follow-up. One year later, she became pregnant and began regularly visiting the nearby obstetric clinic. During the 28th week of pregnancy, on ultrasonography, a 15$\mathrm{cm}$ mass was detected in her abdomen. Although recurrence of the ovarian cancer was suspected, the patient refused to revisit the hospital where she had been previously treated for cancer. She also stopped visiting the obstetric clinic and presented to the hospital where the CD was performed, without a referral.

At our hospital, on the third day after the $\mathrm{CD}$, a left salpingo-oophorectomy was performed in order to control the pleural and peritoneal effusions. The left ovarian tumour measured $27 \times 25 \mathrm{~cm}$ and weighed 2,591 g (Fig. 3a). Histological examinations indicated a poorly differentiated adenocarcinoma whose characteristics were similar to those of the right ovarian tumour resected 2 years previously (Fig. $3 \mathrm{~b}$ ). In addition, gross examination of the placenta revealed a white nodule measuring $1 \times 1 \mathrm{~cm}$ (Fig. 3c), and microscopic examinations confirmed clusters of cancer cells with characteristics similar to the ovarian tumours. However, invasion into the chorionic villi was not detected (Fig. 3d). The final diagnosis was recurrence of adenocarcinoma arising from the mature cystic teratoma of the ovary, involving multiple sites including the placenta. On the 19th day after the $C D$, the patient and her infant were discharged from our hospital.

The patient refused adjuvant chemotherapy and died 3 months after delivery. The infant was a 1,970-g girl, and the Apgar scores recorded were 8 and 8 at 1 and $5 \mathrm{~min}$, respectively. Physical examination at the time of birth and up to the age of 6 years showed no signs of metastasis in the child.

\section{Discussion}

Although the patient outcome was unfavourable with a survival time of only 3 months after delivery, the infant showed no signs of metastasis. These findings are consistent with two previous reports of ovarian cancer concerning placental metastasis, as summarized in Table 1 [4-6]. In a previous report, 93\% of mothers with tumours involving the products of conception, i.e., placenta and foetus, died immediately after delivery [7].

We would like to emphasize that our case involved a pregnant patient who had recurrent ovarian cancer, and most such cases should be treated with hysterectomy and bilateral salpingo-oophorectomy. In addition, we confirm that there was no metastasis detected in her child over a 6-year follow-up period. We suggest that these two arguments supplement the existing findings concerning such cases.

The infant did not receive any metastases from the ovarian cancer of the mother. Although uteroplacental blood flow represents $10 \%$ of maternal cardiac output, it has been suggested that metastatic transmission of maternal tumours to the products of conception is extremely rare, possibly due to the trophoblasts-containing placental barrier and the immune system of the foetus $[7,8]$. During the last decade, four review articles have covered this topic, in which approximately 100 cases have been reported [9-12]. 


\section{Case Reports in Oncology}

Metastatic transmission to the placenta and foetus is most frequently observed in patients with melanoma (30\%), breast cancer (24\%), lung cancer (24\%), and leukaemia and lymphoma (15\%) [7]. Frequency of fatal metastasis involvement is lower than that of placental metastasis, and a total of 17 cases have been reported as follows: melanoma (35\%), leukaemia (17\%), lymphoma (17\%), and lung cancer (17\%). No cases of ovarian cancer with fatal metastasis have been reported, and this may be related to the frequency of tumours diagnosed during pregnancy; the most common malignant tumours detected during pregnancy are breast cancer, cervical cancer, haematological malignancies, melanoma, and lung cancer [4]. Metastases to the products of conception occur via blood vessels and are found in case of tumours whose spread pattern is predominantly haematogenous. As ovarian cancer spreads predominantly via peritoneal dissemination, it seldom metastasizes to the products of conception [3]. However, based on our findings along with two previous cases, advanced ovarian cancer involving multiple organs or having poorly differentiated histology may be likely to metastasize to the products of conception.

Metastasis of a tumour to the foetus is not always obvious at birth. Vertical transmission of a maternal tumour typically becomes apparent 4-5 months after delivery, ranging from birth to 20 months after delivery [8]. We were able to confirm that the infant had no signs of metastasis up to 6 years after birth. There is no routine of following up infants born to parents diagnosed with ovarian cancer involving the placenta, and therefore, it is recommended to assess the status of the offsprings for a minimum of 24 months postnatally [12].

In conclusion, this is a very rare case of recurrent ovarian cancer in a pregnant woman with no planned treatment until delivery. Metastasis to the products of conception with respect to ovarian cancer is relatively uncommon. However, when left untreated, ovarian cancer can metastasize to the placenta. We recommend evaluating the placenta from mothers diagnosed with ovarian cancer. Thus, detailed medical interviews and physical examinations are crucial when a pregnant woman visits a hospital without a referral letter, especially in the third trimester of pregnancy.

\section{Acknowledgements}

We would like to thank Dr. Akihiko Ozaki, Dr. Tetsuya Tanimoto, and Dr. Wataru Isono for their critical reading of the manuscript.

\section{Statement of Ethics}

The authors have no ethical conflicts to disclose.

\section{Disclosure Statement}

The authors have no conflicts of interest declare. 


\section{Case Reports in Oncology}

Honda et al.: Recurrence of Ovarian Cancer with Placental Metastasis: A Case Report

\section{References}

1 Leiserowitz GS, Xing G, Cress R, Brahmbhatt B, Dalrymple JL, Smith LH: Adnexal masses in pregnancy: how often are they malignant? Gynecol Oncol 2006;101:315-321.

-2 Shim MH, Mok CW, Chang KH, Sung JH, Choi SJ, Oh SY, Roh CR, Kim JH: Clinical characteristics and outcome of cancer diagnosed during pregnancy. Obstet Gynecol Sci 2016;59:1-8.

3 Machado F, Vegas C, Leon J, Perez A, Sanchez R, Parrilla J, Abad L: Ovarian cancer during pregnancy: analysis of 15 cases. Gynecol Oncol 2007;105:446-450.

4 Pavlidis N, Pentheroudakis G: Metastatic involvement of placenta and foetus in pregnant women with cancer. Recent Results Cancer Res 2008;178:183-194.

5 Patsner B, Mann WJ Jr, Chumas J: Primary invasive ovarian adenocarcinoma with brain and placental metastases: a case report. Gynecol Oncol 1989;33:112-115.

6 Horner EN: Placental metastases. Case report: maternal death from ovarian cancer. Obstet Gynecol 1960;15:566-572.

7 Ackerman J, Gilbert-Barness E: Malignancy metastatic to the products of conception: a case report with literature review. Pediatr Pathol Lab Med 1997;17:577-586.

8 Herskovic E, Ryan M, Weinstein J, Wadhwani NR: Maternal to fetal transmission of cervical carcinoma Pediatr Radiol 2014;44:1035-1038.

9 Potter JF, Schoeneman M: Metastasis of maternal cancer to the placenta and fetus. Cancer 1970;25:380388.

10 Dildy GA 3rd, Moise KJ Jr, Carpenter RJ Jr, Klima T: Maternal malignancy metastatic to the products of conception: a review. Obstet Gynecol Surv 1989;44:535-540.

11 Jackisch C, Louwen F, Schwenkhagen A, Karbowski B, Schmid KW, Schneider HP, Holzgreve W: Lung cancer during pregnancy involving the products of conception and a review of the literature. Arch Gynecol Obstet 2003;268:69-77.

12 Alexander A, Samlowski WE, Grossman D, Bruggers CS, Harris RM, Zone JJ, Noyes RD, Bowen GM, Leachman SA: Metastatic melanoma in pregnancy: risk of transplacental metastases in the infant. J Clin Oncol 2003;21:2179-2186.
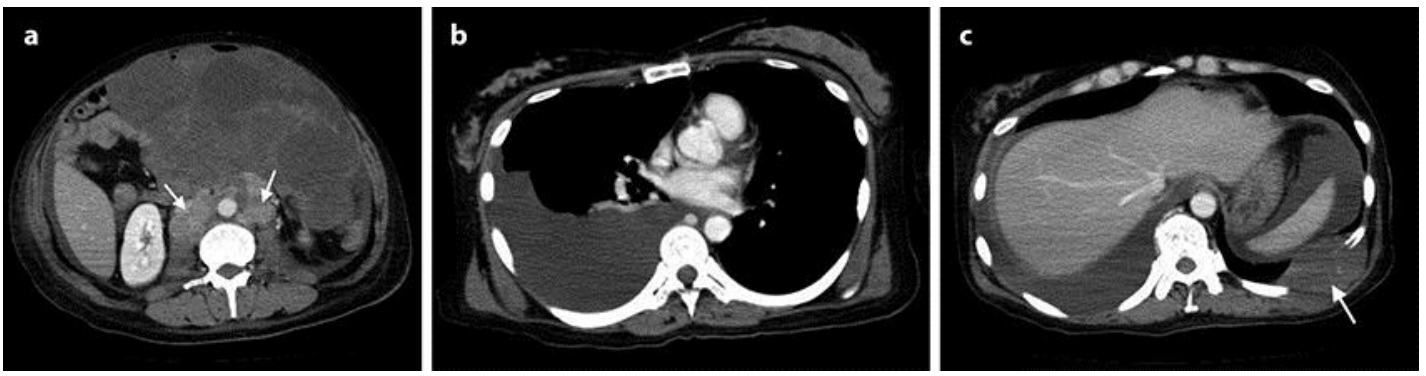

Fig. 1. Contrast-enhanced computed tomography. a An abdominal scan showing a 24-cm solid tumour in the upper left side of the uterus and enlargement of the para-aortic lymph nodes (arrows). $\mathbf{b}$ A chest can showing a large amount of right-sided pleural effusion. c An abdominal scan showing a large amount of peritoneal effusion and a metastatic tumour at the 5th lib (arrow). 


\section{Case Reports in Oncology}
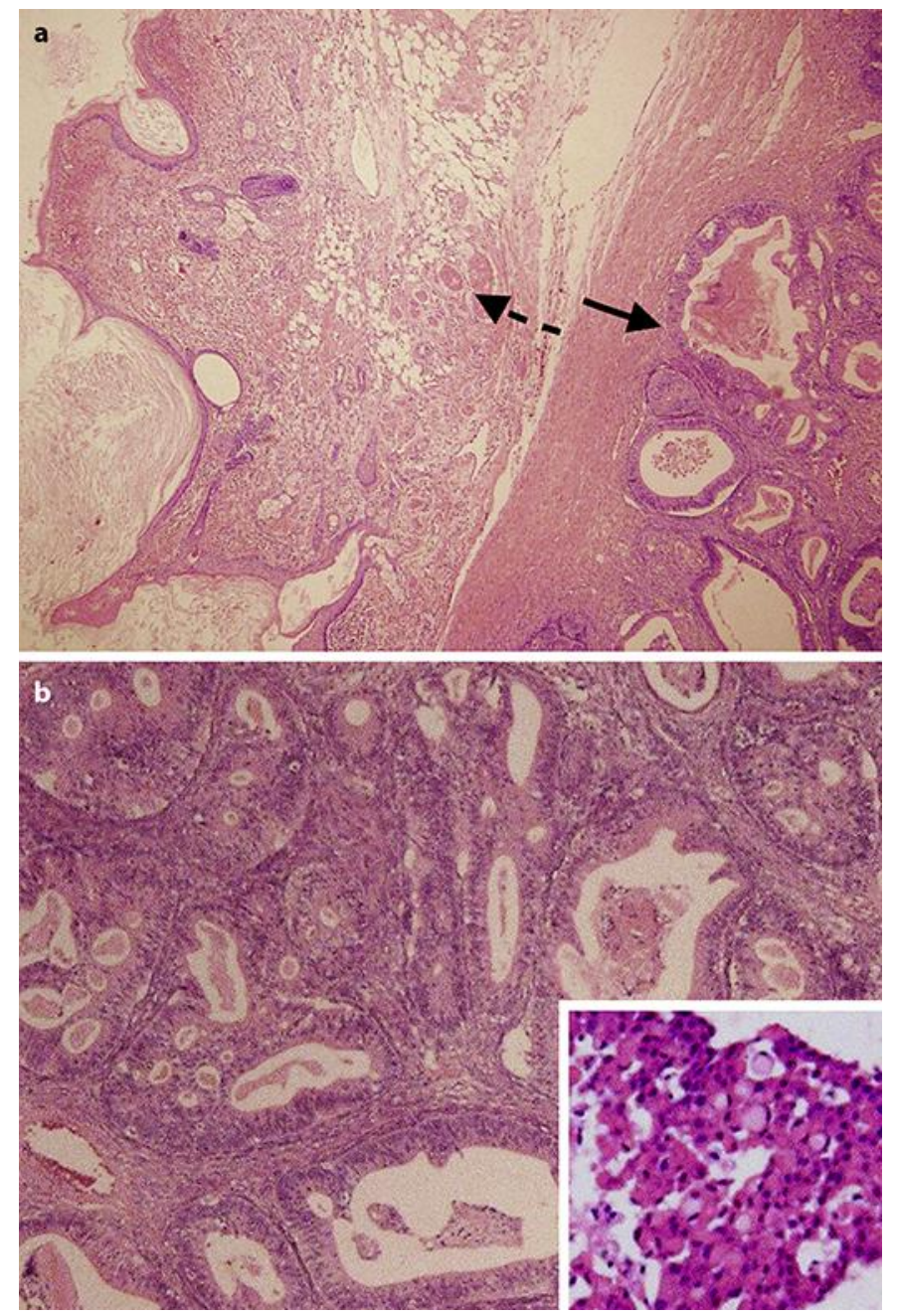

Fig. 2. Pathological findings of the right ovary resected at the age of 37. a Tumour cells (arrow with black line) arising from a mature cystic teratoma (arrow with dashed line) (haematoxylin-eosin stain, magnification $\times 4$ ). $\mathbf{b}$ The tumour was mainly composed of a well-differentiated type of adenocarcinoma (arrow with solid line in a), while a poorly differentiated type of the cells (i.e., signet-ring cells) was observed (haematoxylin-eosin stain, magnification $\times 20$; inset: magnification $\times 40$ ). 


\section{Case Reports in Oncology}
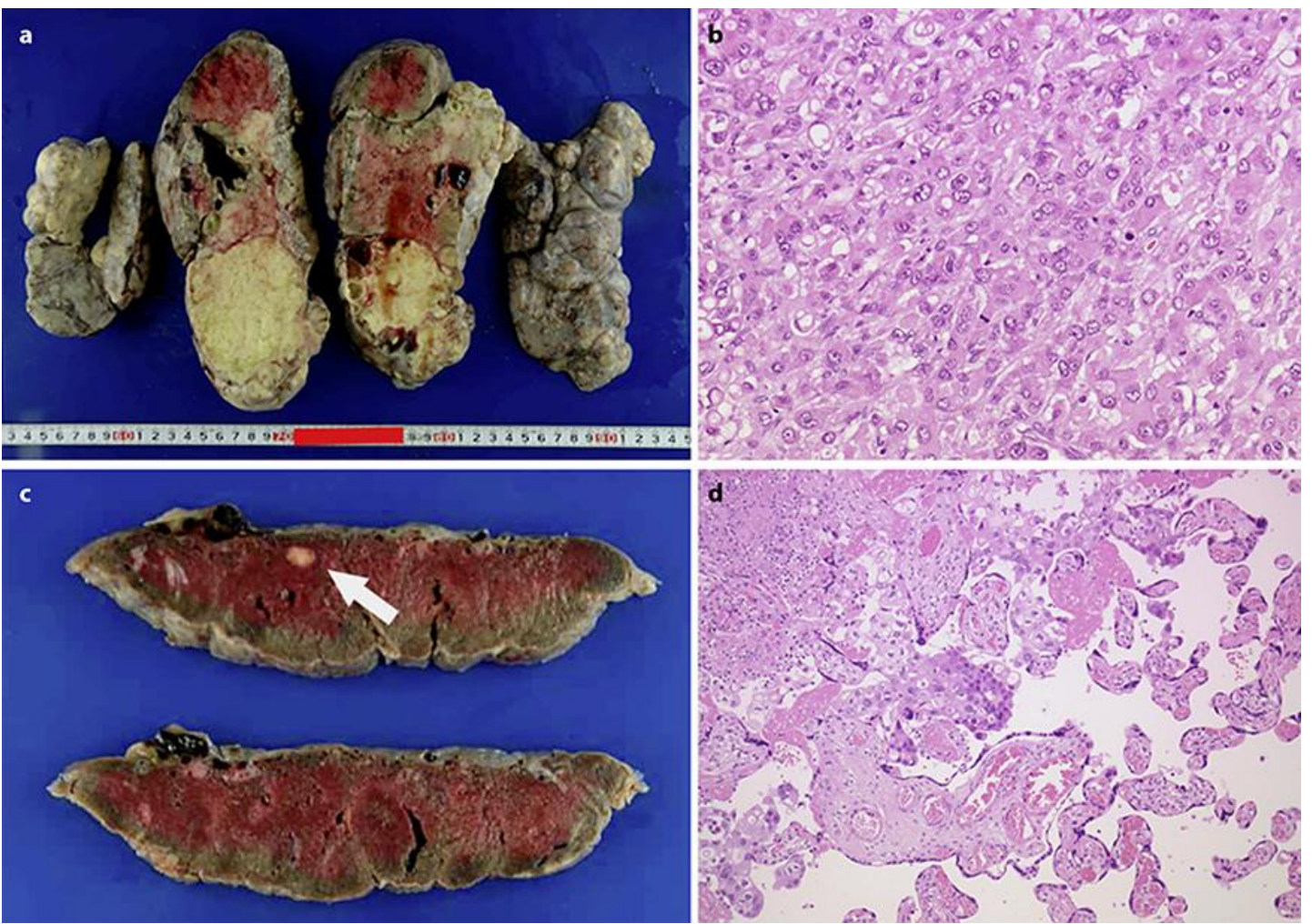

Fig. 3. a Macroscopic findings of the left ovary resected at our hospital. b Pathological findings of the left ovary resected at our hospital. The left ovarian tumour was composed of poorly differentiated adenocarcinoma, the characteristics of which were identical to those observed in the previously resected right ovarian tumour (magnification $\times 20$ ). c Macroscopic findings of the placenta. A white nodule measuring $1 \times 1 \mathrm{~cm}$ was observed in the specimen. $\mathbf{d}$ Pathological findings of placenta. Characteristics and appearance of cancer cells observed in the placenta were similar to those observed in the ovarian tumours (magnification $\times 40$ ). 
Table 1. Clinical and pathological summary of cases of ovarian cancer with placental metastasis

\begin{tabular}{|c|c|c|c|}
\hline Cases & $1[5]$ & $2[4]$ & The present case \\
\hline Age, years & 28 & 28 & 36 \\
\hline Gravida/para & $2 / 1$ & $1 / 0$ & $0 / 0$ \\
\hline Delivery, weeks/mode & $32 / C D$ & $24 / \mathrm{VD}$ & $36 / C D$ \\
\hline Surgical procedure & Left SO & Left SO & $\begin{array}{l}\text { The first: right SO } \\
\text { The second: left SO }\end{array}$ \\
\hline Pathology results & $\begin{array}{l}\text { Papillary and anaplastic } \\
\text { adenocarcinoma with squa- } \\
\text { mous differentiation }\end{array}$ & $\begin{array}{l}\text { Poorly differentiated adenocar- } \\
\text { cinoma }\end{array}$ & $\begin{array}{l}\text { Recurrence of poorly differenti- } \\
\text { ated adenocarcinoma. Arising } \\
\text { from TMT }\end{array}$ \\
\hline Outcome of infant & 2 years: NED & $\begin{array}{l}\text { Stillbirth (no tumor detected in } \\
\text { autopsy) }\end{array}$ & 6 years: NED \\
\hline Outcome of mother & $\begin{array}{l}\text { Dead ( } 3 \text { days after the sur- } \\
\text { gery) }\end{array}$ & $\begin{array}{l}\text { Dead (10 days after the sur- } \\
\text { gery) }\end{array}$ & $\begin{array}{l}\text { Dead ( } 3 \text { months after the } \\
\text { surgery) }\end{array}$ \\
\hline
\end{tabular}

SO, salpingo-oophorectomy ; NED, no evidence of disease; CD, caesarean delivery; VD, vaginal delivery; TMT, teratoma with malignant transformation. 